|| ISSN(online): 2589-8698 || ISSN(print): 2589-868X || International Journal of Medical and Biomedical Studies

Available Online at www.ijmbs.info

PubMed (National Library of Medicine ID: 101738825)

Index Copernicus Value 2017: 40.03

\title{
PARAMETERS AFFECTING STROKE SEVERITY AND OUTCOME IN ACUTE STROKE PATIENTS TREATED WITH IV THROMBOLYSIS
}

\author{
Yıldız Arslan ${ }^{1}$, Mesut Cilli ${ }^{1}$ \\ ${ }^{1}$ Izmir Tepecik Education and Research Hospital Neurology Clinic, Turkey
}

Article Info: Received 16 February 2019; Accepted 12 March. 2019

Cite this article as: Arslan, Y., \& Cilli, M. (2019). PARAMETERS AFFECTING STROKE SEVERITY AND OUTCOME IN ACUTE STROKE PATIENTS TREATED WITH IV THROMBOLYSIS. International Journal of Medical and Biomedical Studies, 3(3).

DOI: https://doi.org/10.32553/ijmbs.v3i3.136

Address for Correspondence: Yıldız Arslan MD., İzmir Tepecik Education and Research Hospital Neurology Clinic, Turkey

Conflict of interest: No conflict of interest.

\section{Abstract}

Aim: Our aim is to evaluate vascular risk factors and laboratory findings in patients treated with IV thrombolysis, to compare these parameters according to neurological findings scored by a National Institutes of Health Stroke Scale (NIHSS) at admission, after 7 days and to investigate the impact of these parameters on stroke severity and outcome at $3^{\text {rd }}$ month.

Methods: We reviewed 53 consecutive acute ischemic stroke patients admitted within 0-4.5 h after stroke onset and treated with IV thrombolysis between 2014 March-2018 May. Patients with acute posterior circulation stroke, and who underwent endovascular intervention after thrombolysis were excluded. Demographic features, vascular risk factors, laboratory findings and hemorrhagic transformation, and NIHSS scores of patients at admission and after 7 days, and also $3^{\text {rd }}$ month mRS scores were recorded.

Results: The mean age of patients was $64.79 \pm 12.26$ and $60.37 \%$ of them were male. Mean NIHSS score at admission was $10.60 \pm 5.16$ and one week after IV r-tPA treatment, the mean score was 7.07 \pm 5.39 . Hemorrhagic transformation was $\mathbf{1 8 . 9 \%}$. The male ratio was significantly higher in mild-moderate stroke group $(p=0.008)$, the prevalence of hypertension, diabetes, hemorrhagic transformation and blood urea levels were also significantly higher in severe stroke group than mild-moderate group ( $p \leq$ 0.05). In addition neutrophil levels were higher in severe group, but not statistically significant. Creatine levels were significantly higher in the poor outcome group (NIHSS difference $<6$ ) after one week.

Conclusion: Female gender, hemorrhagic transformation and high neutrophil levels were found to have impact on stroke severity towards poor prognosis independently.

Key words: IV thrombolysis; stroke severity; clinical outcome; risk factors

\section{1-INTRODUCTION:}

Thrombolysis for acute ischemic stroke (AIS) is an acute therapy that can reduce stroke associated disability. Randomized controlled studies have shown that intravenous recombinant tissue plasminogen activator (IV r-tPA) therapy administered within the first 3 hours after AIS led to a $10 \%$ to $30 \%$ decrease in the mortality and disability of patients at 3 to 6 months posttreatment $(1,2,3)$. More recently, results from the European Cooperative Acute Stroke Study 
(ECASS) III randomized trial of IV rt-PA at 3 to 4.5 hours from stroke onset proved that it is also effective beyond 3 hours in selected group of patients $(3,4)$, but that the magnitude of benefit diminishes with increasing treatment delay (5).

To determine factors associated with stroke severity and outcome after IV r-tPA treatment can be important in predicting the outcome and selection of eligible patients, also management of the associated factors for a better 3-6 month outcome (3). Predicting the groups for which this therapy will be most effective is important for minimizing mortality and improving functional outcomes (2). Numerous clinical and laboratory variables have been identified as potential predictors of clinical outcome. Age, stroke severity, hemorrhagic transformation, infarct location, comorbid conditions such as vascular risk factors, clinical findings and laboratory tests including renal functions and coagulation tests may influence stroke prognosis and outcome (6, 7). Furthermore, it was suggested that infarct volume, as measured by $\mathrm{CT}$, has also been shown to correlate with clinical outcome after 7 days of treatment and may independently predict the clinical outcome at the end of the third month $(3,7)$.

We aimed to evaluate vascular risk factors and laboratory findings in patients treated with IV $\mathrm{r}$ tPA, to compare these parameters according to neurological findings scored by a National Institutes of Health Stroke Scale (NIHSS) at admission and after 7 days and also third month modified rankin scores (mRS) and to investigate the effect of these parameters on stroke severity and outcome.

\section{2-METHODS:}

\section{2-1: Study Groups:}

The study enrolled 53 consecutive acute ischemic stroke patients treated with IV r-tPA within 4.5 hours of symptom onset and who were hospitalized at least seven days, between 2014 March-2018 May retrospectively.

Patients with acute posterior circulation stroke, and who underwent endovascular intervention after IV r-tPA were excluded from the study. IV rtPA was given according to 'AHA/ASA Guideline' Guidelines for the Early Management of Patients With Acute Ischemic Stroke'; $10 \%$ of the total dose $(0.9 \mathrm{mg} / \mathrm{kg}$, maximum dose $=90 \mathrm{mg})$ was administered as a bolus dose and the rest was infused in one hour (8).

Demographic features (age, gender), vital and laboratory findings (renal function tests, coagulation tests, liver enzymes, glucose, uric acids, complete blood count), previous or newly diagnosed vascular risk factors (hypertension $(\mathrm{HT})$, diabetes mellitus (DM), atrial fibrillation $(\mathrm{AF})$, previous stroke (PS), coronary artery disease (CAD)), hemorrhagic transformation in a week, and NIHSS scores of patients on admission and after 7 days, the time between symptom onset and the treatment (0-3 $\mathrm{h}$ and 3-4.5 h) and also third month mRS scores were recorded.

In supratentorial infarcts, NIHSS cut-off value for poor outcome was accepted 10, as described by Yoshimura et al. in 2018 from the pooled data of Enhanced Control of Hypertension and Thrombolysis Stroke Study (ENCHANTED) trial (9). Accordingly, NIHSS $\geq 10$ was accepted as poor outcome and $<10$ good outcome in our study population as well. The neurological improvement in NIHSS $\geq 6$ was defined as good response and $<6$ was considered as poor response after IV rt PA treatment. Third month functional outcomes were indicated as good outcome ( $m R S \leq 2)$ and poor outcome $(m R S>2)$.

All parameters described above were compared between the groups NIHSS $<10$ and NIHSS $\geq 10$, NIHSS difference $<6$ and NIHSS difference $\geq 6$, $m R S \leq 2$ and $m R S>2$ accordingly.

This retrospective study was carried out considering Helsinki Declaration criteria, and approved by the local ethics committee of education and research hospital.

\section{2-2: Laboratory tests:}

In the first 24 hours after admission, 10-ml blood samples were obtained for complete blood count 
(CBC) and total biochemistry via antecubital vein into two tubes by forming mild stasis. Glucose, urea, creatine, uric acids, CBC (hemoglobin, platelet, leucocytes, neutrophil) aPTT, PT, INR, ALT, AST levels were analyzed for each patient.

\section{2-3: Statistical analysis:}

SPSS version 23.0 (IBM Corporation; Chicago, Illinois) was utilized for all statistical analyses. Descriptive statistics and mean values were calculated. Mann Whitney $U$ and Student's ttests were used to assess parametric variables. Chi-square test was used to assess nonparametric variables. Binary logistic regression analyses were utilized to evaluate impact of variables on the groups according to stroke outcome and severity. P-values $<0.05$ were considered to indicate statistical significance.

\section{2-4: Results:}

The mean age of patients was $64.79 \pm 12.26$ and $60.37 \%$ of them was male. Mean NIHSS score at admission was $10.60 \pm 5.16$ and one week after IV r-tPA treatment, the mean score was 7.07 \pm 5.39 . $18.86 \%(n=10)$ of the patients died in three months (mRS=6).

The ratios of vascular risk factors were $\mathrm{HT}$ : 56.6\%, DM: $30.2 \%$, AF: $39.6 \%$, PS: $13.2 \%$, CAD: $32.1 \%$ respectively. Admission in first $3 \mathrm{~h}$ was $84.9 \%$ and high enough for good response to IV $r$-tPA therapy. Hemorrhagic transformation was $18.9 \%$, low as expected in this group.

Table 1: Comparison of parameters between groups according to stroke severity

\begin{tabular}{|c|c|c|c|}
\hline Parameters & $\begin{array}{l}\text { Group 1 } \\
\text { (NIHSS }<10) \text { n: } 27\end{array}$ & \begin{tabular}{|l|} 
Group 2 \\
(NIHSS $\geq 10)$ n: 26
\end{tabular} & P Value \\
\hline Age & $62.66 \pm 12.66$ & $67.00 \pm 11.66$ & 0.20 \\
\hline Gender (\%male) & $77.8 \%$ & $42.3 \%$ & 0.008 \\
\hline AF (\%) & $29.6 \%$ & $50 \%$ & 0.13 \\
\hline HT & $44.4 \%$ & $69.2 \%$ & 0.06 \\
\hline DM & $18.5 \%$ & $42.3 \%$ & 0.05 \\
\hline PS & $18.5 \%$ & $7.7 \%$ & 0.24 \\
\hline CAD & $22.2 \%$ & $42.3 \%$ & 0.11 \\
\hline First $3 \mathrm{~h}$ & $85.2 \%$ & $84.6 \%$ & 0.95 \\
\hline Hemorrhagic T. & $7.4 \%$ & $30.8 \%$ & 0.03 \\
\hline Urea & $33.74 \pm 12.09$ & $45.61 \pm 18.83$ & 0.008 \\
\hline Creatine & $0.98 \pm 0.29$ & $1.09 \pm 0.37$ & 0.22 \\
\hline Glucose & $148.18 \pm 59.78$ & \begin{tabular}{|l|}
$183.65 \pm 97.62$ \\
\end{tabular} & 0.12 \\
\hline aPTT & $25.56 \pm 9.21$ & $24.58 \pm 4.66$ & 0.63 \\
\hline INR & $1.05 \pm 0.14$ & $1.07 \pm 0.10$ & 0.53 \\
\hline PT & $12.75 \pm 1.74$ & $13.12 \pm 1.31$ & 0.39 \\
\hline WBC & $8780 \pm 2723$ & $9965 \pm 2692$ & 0.11 \\
\hline Neutrophil & $5588 \pm 2364$ & $6883 \pm 2805$ & 0.07 \\
\hline WBC/Neutrophil & $1.64 \pm 0.31$ & $1.53 \pm 0.31$ & 0.20 \\
\hline Lymphocytes & $2305 \pm 723$ & $2199 \pm 827$ & 0.62 \\
\hline Hgb. & $13.78 \pm 1.64$ & $13.49 \pm 2.41$ & 0.61 \\
\hline Plt. & $238,592 \pm 53,528$ & $253,269 \pm 128,367$ & 0.58 \\
\hline Uric acids & $5.57 \pm 1.71$ & $5.81 \pm 2.15$ & 0.64 \\
\hline AST & $23.14 \pm 13.52$ & $23.88 \pm 10.80$ & 0.82 \\
\hline ALT & $16.11 \pm 7,80$ & $17.84 \pm 9,62$ & 0.47 \\
\hline
\end{tabular}


NIHSS: national institute health stroke scale. AF: atrial fibrillation HT: hypertension DM: diabetes mellitus. PS: previous stroke. CAD: coronary artery disease. aPTT: activated partial thromboplastin time. INR: international normalized ratio. PT: prothrombin time. WBC: white blood cell.

Table 1 show. Comparison of parameters between groups according to stroke severity, Vascular and laboratory parameters were compared between two groups of NIHSS >10 (group 1) and NIHSS $\leq 10$ (group 2) at the time of admission were stated in Table 1. The male ratio was significantly higher in Group 1 ( $p=0.008)$, the prevalence of HT, DM, hemorrhagic transformation and blood urea levels were also significantly higher in Group 2 than Group 1 ( $p \leq 0.05)$. In addition neutrophil levels was higher in Group 2, but not significantly different ( $p=0.07)$.

Table 2: Comparison of parameters between groups according to clinical outcome after r-tPA therapy

\begin{tabular}{|l|l|l|l|}
\hline Parameters & $\begin{array}{l}\text { Group 1 } \\
\text { (NIHSS diff. } \geq 6 \text { ) n:23 }\end{array}$ & $\begin{array}{l}\text { Group 2 } \\
\text { (NIHSS diff. < 6) n:30 }\end{array}$ & P Value \\
\hline Age & $65.43 \pm 12.15$ & $64.30 \pm 12.53$ & 0.74 \\
\hline Gender (\%male) & $56.5 \%$ & $63.3 \%$ & 0.61 \\
\hline AF (\%) & $43.5 \%$ & $36.7 \%$ & 0.61 \\
\hline HT (\%) & $60.9 \%$ & $53.3 \%$ & 0.58 \\
\hline DM (\%) & $39.1 \%$ & $23.3 \%$ & 0.21 \\
\hline PS (\%) & $8.7 \%$ & $16.7 \%$ & 0.39 \\
\hline CAD (\%) & $34.8 \%$ & $30.0 \%$ & 0.71 \\
\hline First 3 h (\%) & $82.6 \%$ & $86.7 \%$ & 0.68 \\
\hline Hemorrhagic T. & $17.4 \%$ & $20.0 \%$ & 0.81 \\
\hline Urea & $36.10 \pm 13.30$ & $44.08 \pm 19.74$ & 0.08 \\
\hline Creatine & $0.94 \pm 0.19$ & $1.15 \pm 0.43$ & 0.04 \\
\hline Glucose & $170.26 \pm 93.16$ & $162.00 \pm 73.34$ & 0.71 \\
\hline aPTT & $24.40 \pm 4.21$ & $25.60 \pm 9.01$ & 0.55 \\
\hline INR & $1.04 \pm 0.08$ & $1.08 \pm 0.14$ & 0.18 \\
\hline PT & $12.63 \pm 1.28$ & $13.17 \pm 1.70$ & 0.21 \\
\hline WBC & $9634 \pm 2380$ & $9152 \pm 3023$ & 0.53 \\
\hline Neutrophil & $6324 \pm 2097$ & $6146 \pm 3035$ & 0.81 \\
\hline WBC/Neutrophil & $1.59 \pm 0.32$ & $1.59 \pm 0.31$ & 0.99 \\
\hline Lymphocytes & $2346 \pm 834$ & $2181 \pm 724$ & 0.44 \\
\hline Hgb. & $13.24 \pm 1.99$ & $13.94 \pm 2.06$ & 0.21 \\
\hline Plt. & $261,347 \pm 133,303$ & $233,866 \pm 55,253$ & 0.31 \\
\hline Uric acids & $5.50 \pm 1.74$ & $5.83 \pm 2.07$ & 0.54 \\
\hline AST & $16.56 \pm 9.17$ & $17.26 \pm 8.46$ & 0.77 \\
\hline ALT & $21.86 \pm 7.64$ & $24.76 \pm 14.71$ & 0.39 \\
\hline & & & \\
\hline & & 179 & \\
\hline
\end{tabular}

NIHSS: national institute health stroke scale. AF: atrial fibrillation HT: hypertension DM: diabetes mellitus. PS: previous stroke. CAD: coronary artery disease. aPTT: activated partial thromboplastin time. INR: international normalized ratio. PT: prothrombin time. WBC: white blood cell.

Table 2 show. Comparison of parameters between groups according to clinical outcome after r-tPA therapy. Two groups were composed according to the difference between NIHSS scores on admission 
and one week after IV rt-PA therapy as presented in Table 2. Blood creatine levels were significantly higher in Group 2 (NIHSS difference <6). Mean level of urea was also higher, but not significantly different $(p=0.08)$.

Table 3: Comparison of vascular risk factors between groups according to functional outcome at the $3^{\text {rd }}$ month.

\begin{tabular}{|l|l|l|l|}
\hline Parameters & $\begin{array}{l}\text { Group 1 } \\
\text { (mRS } \leq \mathbf{2}) \mathbf{n : 2 3}\end{array}$ & $\begin{array}{l}\text { Group 2 } \\
\text { (mRS > 2) n:30 }\end{array}$ & P Value \\
\hline Age & $63.0 \pm 14.08$ & $66.16 \pm 10.71$ & 0.35 \\
\hline Gender (\%male) & $73.9 \%$ & $50.0 \%$ & 0.07 \\
\hline AF (\%) & $43.5 \%$ & $36.7 \%$ & 0.61 \\
\hline HT (\%) & $43.5 \%$ & $66.7 \%$ & 0.09 \\
\hline DM (\%) & $21.7 \%$ & $36.7 \%$ & 0.24 \\
\hline PS (\%) & $8.7 \%$ & $16.7 \%$ & 0.39 \\
\hline CAD (\%) & $26.1 \%$ & $36.7 \%$ & 0.41 \\
\hline First 3 h (\%) & $82.6 \%$ & $86.7 \%$ & 0.68 \\
\hline Hemorrhagic T. & $17.4 \%$ & $20.0 \%$ & 0.81 \\
\hline Urea & $39.82 \pm 20.57$ & $39.36 \pm 13.42$ & 0.92 \\
\hline Creatine & $1.10 \pm 0.45$ & $0.98 \pm 0.21$ & 0.22 \\
\hline Glucose & $156.04 \pm 95.76$ & $172.90 \pm 70.07$ & 0.46 \\
\hline Uric acids & $5.68 \pm 1.79$ & $5.69 \pm 2.05$ & 0.98 \\
\hline
\end{tabular}

mRS: modified rankin scores. AF: atrial fibrillation HT: hypertension DM: diabetes mellitus. PS: previous stroke. CAD: coronary artery disease.

Table 3 show. Comparison of vascular risk factors between groups according to functional outcome at the $3^{\text {rd }}$ month. The patients were also analyzed according to mRS after three months and there was no significantly different parameter between two groups ( $m R S \leq 2$ (group 1) and $m R S>2$ (group 2)) as shown in Table 3. The ratio of males in Group 1 and prevalence of HT in Group 2 were higher, but not statistically significant ( $p>0.05$ ).

Table 4: Binary logistic regression analysis of significant parameters

\begin{tabular}{|l|l|l|l|l|l|l|l|l|}
\cline { 8 - 11 } & \multicolumn{9}{|c|}{$\mathbf{9 5 \% C l}$ for Exp } \\
\hline Gender (male) & B & S.E & Wald & df & Sig. & Exp(B) & Lower & Upper \\
\hline HT & 1.13 & 0.941 & 5.148 & 1 & $\mathbf{0 . 0 2 3}$ & 0.118 & 0.019 & 0.748 \\
\hline DM & 1.70 & 1.134 & 1.246 & 1 & 0.264 & 3.544 & 0.38 & 32.68 \\
\hline Hemorrhagic T. & 3.36 & 1.381 & 5.923 & 1 & $\mathbf{0 . 0 1 5}$ & 28.840 & 1.924 & 432.318 \\
\hline Urea & 0.024 & 0.029 & 0.713 & 1 & 0.398 & 1.025 & 0.968 & 1.085 \\
\hline Neutrophil & 0.000 & 0.000 & 5.208 & 1 & $\mathbf{0 . 0 2 2}$ & 1.000 & 1.000 & 1.001 \\
\hline
\end{tabular}

HT: hypertension DM: diabetes mellitus

Table 4 show. Binary logistic regression analysis of significant parameters. Logistic regression analyses of two groups (NIHSS $\leq 10$ and NIHSS > 10) were performed as shown in Table 4. Female gender, hemorrhagic transformation and high neutrophil levels were found to have impact on stroke severity towards poor prognosis independently. 
In addition, according to logistic regression analyses of the other model with two groups (NIHSS difference $<6$, NIHSS difference $\geq 6$ ) revealed that urea or creatine levels were not independent risk factors for stroke prognosis after one week.

\section{3-DISCUSSION:}

Thrombolysis is at the milestone of modern management of AIS, with good evidence of its efficacy within 4.5 hour of symptom onset. Intracranial hemorrhagic transformation is the major complication associated with thrombolysis in AIS, and key factors increasing risk of hemorrhage include increasing age, high blood pressure, diabetes and stroke severity $(1,8)$.

In this retrospective study, we did not demonstrate any meaningful differences between mean ages of all defined groups. But there was a significant difference in terms of gender. The results showed that the ratio of males was higher than females in the study population (60.37\%) and also significantly higher in mild-moderate stroke group. Furthermore, males had better functional outcome than females according to mRS scores after three months. In addition, we determined that female gender was an independent risk factor for stroke severity in our study ( $p=0.023-$ Exp. (B):0.118(95\% Cl [0.019-0.748]).

In accordance with the results of our study, in literature it was proven that the prevalence of stroke in females is lower than males, and several studies have shown that females suffered from more severe strokes, had higher short-term mortality than males, but long-term sex differences in mortality persist up to 5 years after stroke $(10,11,12)$. Ghosh et al. also reported that female patients had significantly higher incidence of poor outcome, but female gender was not a significant predictor of stroke severity and mortality (6). Additionally, in other studies, parameters of worse functional outcome at 1- and 5-year follow-up, greater mental impairment, and lower quality of life were determined in females compared to males (10, 13).

In our study, there was no difference between ratios of males and females who had favorable outcome at one week following thrombolysis treatment (NIHSS diff. $\geq 6$; $56.5 \%$ in men versus $43.5 \%$ in women; $p=0.61$ ). In a pooled analysis of three major randomized clinical trials of IV r-tPA, Kent et al. showed that the proportion of males and females with good functional outcomes at 90 days following treatment was similar, whereas among the placebo group, significantly fewer women had good outcomes (15).

We demonstrated that HT and DM were more prevalent in severe stroke group (NIHSS $\geq 10$ ) significantly. Besides HT was more prevalent, but not statistically significant in the patients with poor outcome after three months (mRS >2) $(p=0.09)$.

Observational clinical studies reported that stroke severity measured by the NIHSS was associated with elevated blood pressure (BP) during the acute phase, and predicted poor clinical outcomes of ischemic stroke (16). Further high systolic BP is linked with worse clinical outcome in patients with AIS treated with thrombolysis. Higher systolic BP levels are associated with poor rate of recanalization in acute stroke patients treated with thrombolysis (17).

In addition, diabetes on admission is correlated with stroke progression, poor functional outcomes and mortality. It has been also associated with poor outcomes after reperfusion therapy or hemorrhagic transformation following initial ischemic stroke occurrence $(18,19,20)$. Hyperglycemia is independently related with larger final infarct volume; disrupts collateral circulation of ischemic penumbra, increases the reperfusion injury, and has harmful effects on the outcome in stroke with major vessel occlusion via increasing blood brain barrier permeability, cerebral edema, and decreasing fibrinolytic activity after thrombolysis $(2,3,21)$. 
In the present study, hemorrhagic transformation and mean urea levels were also determined significantly higher in severe stroke group $(P<0.05)$. We also found higher urea and creatine levels in the group of poor prognosis (NIHSS difference <6) one week after thrombolysis. Renal dysfunction may affect outcome and induce renal anemia, oxidative stress, inflammation, endothelial dysfunction, and paradoxical effects on hemostasis in IV r-tPA treated patients (22).

In literature, it was suggested that chronic kidney disease (CKD) is associated with increased risk of ischemic and hemorrhagic stroke, its severity and the risk of poor outcome and mortality in general population and its presence is an independent risk factor for a worse prognosis after a stroke $(22,23,24,25)$. A possible explanation of cerebrorenal interaction may be because of the similar anatomical and functional vasoregulation of microvasculature features $(24,26)$.

Moreover hemorrhagic transformation was significantly higher in severe stroke group, which is an expected result and also in logistic regression analysis it was concluded as an independent risk factor for stroke severity $(p=0.015)$.

On the other hand, mean level of neutrophil was higher in the severe stroke group on admission, but not significantly different $(p=0.07)$, however it was determined as an independent risk factor for stroke severity in acute stage. We also analyzed leucocytes/ neutrophil ratio in our study, but there was no significant difference among the groups.

Clinical evidences have confirmed that early higher leukocyte and neutrophil counts are associated with larger infarct volumes and increased stroke severity in the acute stage of ischemia $(27,28,29)$. High neutrophil count in patients with AIS is related to poor prognosis at 3 months, while low lymphocyte count is predictive of poor neurological improvement during the first week after admission. If neutrophil infiltration is inhibited, the infarct volume may be significantly reduced and neurological outcome is improved $(28,29)$.

There are some limitations of this study, it was retrospective and the number of the cases was small.

In conclusion according to our results; gender, $H T$, DM, renal dysfunction and neutrophil counts are the predictive factors of stroke severity on admission. Patients with HT are associated with worse prognosis at third months. Additionally, urea and creatine levels may be related with poor outcome after one week for the patients treated with IV r-tPA. Hemorrhagic transformation, female gender and neutrophil counts are the independent factors of stroke severity on admission. Further prospective randomized larger studies are needed to prove these findings.

\section{REFERENCES}

1. Zaheer Z,Robinson $T$, Mistri AK. 'Thrombolysis in acute ischaemic stroke: an update' Ther Adv Chronic Dis 2011; 2:119131.

2. Çetiner $M$, Aydın HE, Güler M, Kabay SC, Zorlu Y. 'Predictive Factors for Functional Outcomes After Intravenous Thrombolytic Therapy in Acute Ischemic Stroke' Clinical and Applied Thrombosis/Hemostasisisepi 2018; 24:171-177.

3. Eryıldız ES, Özdemir AÖ. 'Factors Associated with Early Recovery after Intravenous Thrombolytic Therapy in Acute Ischemic Stroke' Arch Neuropsychiatry 2018; 55: 80-83.

4. Khatri P, Abruzzo T, Yeatts SD, Nichols C, Broderick JP, Tomsick TA, For the IMS I and II Investigators. 'Good clinical outcome after ischemic stroke with successful revascularization is time dependent' Neurology 2009; 73: $1066-1072$.

5. Emberson J, Lees KR, Lyden P, Blackwell L, Albers G, Bluhmki E, Brott T, Cohen G, Davis S, Donnan G, Grotta J, Howard G, Kaste M, Koga $M$, Kummer R, Lansberg $M$, Lindley RI, Murray G, Olivot JM, Parsons M, Tilley B, 
Toni D, Toyoda K, Wahlgren N, Wardlaw J, Whiteley W, del Zoppo GJ, Baigent C, Sandercock P, Hacke W; for the Stroke Thrombolysis Trialists' 'Collaborative Group Effect of treatment delay, age, and stroke severity on the effects of intravenous thrombolysis with alteplase for acute ischemic stroke: a meta-analysis of individual patient data from randomised trials' Lancet 2014; 384: 1929-1935.

6. Ghosh KC, Bhattacharya R, Ghosh S, Mahata M, Das S, Das S, Mondal PG. 'Predictors of severity and outcome and roles of intravenous thrombolysis and biomarkers in first ischemic stroke' Neuroimmunol Neuroinflammation 2018;5:38. http:// dx.doi.org/10.20517/2347-8659.2018.28.

7. Johnston KC, Connors AF, Wagner DP, Knaus WA, Wang XQ, Clarke Haley E. ;išpifor the Randomized Trial of Tirilazad Mesylate in Acute Stroke (RANTTAS) Investigators. 'A Predictive Risk Model for Outcomes of Ischemic Stroke' Stroke 2000; 31:448-455.

8. Jauch EC, Saver JL, Adams HP, Bruno A, Connors JJ, Demaerschalk BM, Khatri $P$, McMullan PW, Qureshi Al, Rosenfield K, Scott PA, Summers DR,. Wang DZ, Wintermark $\mathrm{M}$, Yonas $\mathrm{H}$. 'Guidelines for the Early Management of Patients With Acute Ischemic Stroke A Guideline for Healthcare Professionals From the American Heart Association/American Stroke Association' Stroke. 2013;44: 870-947.

9. Yoshimura S, Lindley RI, Carcel C, Sato S, Delcourt C, Wang X, Chalmers J, Anderson CS, for the ENCHANTED Investigators. 'NIHSS cut-point for predicting outcome in supra-vs infratentorial acute ischemic stroke' Neurology 2018;00:1-7. doi:10.1212/ WNL. 0000000000006437

10. Phan HT, Reeves MJ, Blizzard CL, Thrift AG, Cadilhac DA, Sturm J, Otahal $P$,; Rothwell $P$, Bejot Y, Cabral NL, Appelros P, K orv J, Vibo R, Minelli C, Gall SL, 'Sex Differences in Severity of Stroke in the INSTRUCT Study: a Meta-Analysis of Individual Participant Data' J Am Heart Assoc. 2019;8:e010235.
11. Zou C, Wei C, Wang Z, Jin Y. 'Sex differences in outcomes and risk factors among elderly patients with ischemic stroke' Oncotarget, 2017;8: 104582-104593.

12. Ong CT, Wong YS, Sung SF, Wu CS, Hsu YC, Su YH, Hung LC. 'Sex-related differences in the risk factors for in-hospital mortality and outcomes of ischemic stroke patients in rural areas of Taiwan' PLoS ONE 2017,12(9):e0185361.

13. Li W, Valenzuela JP, Ward R, Abdelbary $M$, Dong G, Fagan SC, Ergul A. 'Post-stroke neovascularization and functional outcomes differ in diabetes depending on severity of injury and sex: Potential link to hemorrhagic transformation' Experimental Neurology 2019;311:106-114.

14. Zrelak PA. 'Sex-Based Differences in Symptom Perception and Care-Seeking Behavior in Acute Stroke' Perm J 2018; 22:18-42.

15. Lisabeth LD, Baek J, Morgenstern LB, Reeves MJ, Brown DL, Zahuranec DB, Smith MA, Sánchez BN. 'Sex differences in the impact of acute stroke treatment in a populationbased study: a sex-specific propensity score approach' Ann Epidemiol. 2017; 27: 493498.

16. Bu X, Li C, Zhang $Y, X u T$, Wang $D$, Sun $Y$, Peng $H, X u T$, Chen CS, Bazzano LA, Chen J, He J. on behalf of the CATIS Investigators. 'Early Blood Pressure Reduction in Acute Ischemic Stroke with Various Severities: A Subgroup Analysis of the CATIS Trial' Cerebrovasc Dis 2016; 42: 186-195.

17. Rusanen H, Saarinen JT, Sillanpää N.'The Association of Blood Pressure and Collateral Circulation in Hyperacute Ischemic Stroke Patients Treated with Intravenous Thrombolysis' Cerebrovasc Dis 2015;39: 130-137.

18. Nikneshan D, Raptis R, Pongmoragot J, Zhou L, Johnston C, Saposnik G, on behalf of the investigators of the registry of the canadian stroke network (RCSN) and the stroke outcomes research Canada (SORCAN) 
working group. 'Predicting clinical outcomes and response to thrombolysis in acute stroke patients with diabetes' Diabetes care 2013; 36: 2041-2047.

19. Lee KJ, Lee JS, Jung KH. 'Interactive effect of acute and chronic glycemic indexes for severity in acute ischemic stroke patients' BMC Neurology 2018;18:105. https:// doi.org/10.1186/s12883-018-1109-1.

20. McCall SJ, Alanazi TA, Clark $A B$, Musgrave $\mathrm{SD}$, Bettencourt-Silva JH, Bachmann MO, Metcalf AK, Bowles KM, Mamas MA, Potter JF, Myint PK. Hyperglycaemia and the SOAR stroke score in predicting mortality' Diabetes \& Vascular Disease Research 2018; 15: 114-121.

21. Bas DF, Özdemir AÖ, Çolak $E$, Kebapci $N$. 'Higher Insulin Resistance Level is Associated with Worse Clinical Response in Acute Ischemic Stroke Patients Treatedisepi: with Intravenous Thrombolysis' Transl. Stroke Res. 2016; 7:167-171.

22. Gensicke H, Zinkstok SM, Roos YB, et al. 'IV thrombolysis and renal function' Neurology 2013; 81; 1780-1788.

23. Sadeghi-Hokmabadi E, Baş DF, Farhoudi M, Taheraghdam A, Savadi Oskouei D, Yazdchi M, Hashemilar M, Uzuner N, Mirnour R, Colak E, Özdemir AÖ. 'Renal Dysfunction Is an Independent Risk Factor for Poor Outcome in Acute Ischemic Stroke Patients Treated with Intravenous Thrombolysis: A New Cutoff Value' Stroke Res Treat. 2017; Article ID 2371956, 6 pages http://dx.doi.org/10.1155/2017/2371956.

24. Castro P, Azevedo E, Rocha I, Sorond F, Serrador JM. 'Chronic kidney disease and poor outcomes in ischemic stroke: is impaired cerebral autoregulation the missing link?'BMC Neurology 2018; 18: 21. https://doi.org/10.1186/s12883-018-1025-4.

25. Ovbiagele B, Schwamm LH, Smith EE, GrauSepulveda MV, Saver JL, Bhatt DL, Hernandez AF, Peterson ED, Fonarow GC. 'Patterns of Care Quality and Prognosis Among Hospitalized Ischemic Stroke Patients With Chronic Kidney Disease' J. Am Heart Assoc. 2014; 3: e000905 doi: 10.1161/ JAHA. 114.000905.

26. Wu CL, Tsai CC, Kor CT, Tarng DC, Lian IB, Yang TH, Chiu PF, Chang CC. 'Stroke and Risks of Development and Progression of Kidney Diseases and End- Stage Renal Disease: A Nationwide Population-Based Cohort Study' PLOS ONE DOI:10.1371/ journal.pone.0158533.

27. Kumar AD, Boehme AK, Siegler JE, Gillette $M$, Albright KC, Martin-Schild S, 'Leukocytosis in Patients with Neurologic Deterioration after Acute Ischemic Stroke is Associated with Poor Outcomes' I Stroke Cerebrovasc Dis. 2013; 22: e111-e117. doi:10.1016/ j.jstrokecerebrovasdis. 2012.08.008.

28. Strecker JK, Schmidt A, Schabitz W-R, Minnerup J. 'Neutrophil granulocytes in cerebral ischemia- Evolution from killers to key players' Neurochemistry International 2017; 107: 117-126.

29. Zhao L, Dai Q, Chen X, Li S, Shi R, Yu S, Yang $F$, Xiong $Y$, Zhang R. 'Neutrophil-toLymphocyte Ratio Predicts Length of Stay and Acute Hospital Cost in Patients with Acute Ischemic Stroke' I Stroke Cerebrovasc Dis. 2016 ;25:739-744. 